\title{
Oxygen Vacancies: Effective Strategy to Boost Sodium Storage of Amorphous Electrode Materials
}

Yang Xu, ${ }^{a}$ Min Zhou, ${ }^{a}$ Chenglin Zhang, ${ }^{b}$ Chengliang Wang, ${ }^{a, c}$ Liying Liang, ${ }^{a}$ Yaoguo Fang, ${ }^{a}$ Minghong $W u,{ }^{b}$ Lin Cheng, ${ }^{a}$ Yong Lei ${ }^{*}, a, b$

${ }^{a}$ Institute für Physik \& IMN MacroNano (ZIK), Technische Universität Ilmenau, Ilmenau 98693, Germany

b Institute of Nanochemistry and Nanobiology, School of Environmental and Chemical Engineering, Shanghai University, Shanghai 200444, P. R. China

${ }^{\mathrm{c}}$ School of Optical and Electronic Information, Huazhong University of Science and Technology, Wuhan 430074, P. R. China

* Corresponding author. Email address: yong.lei@ tu-ilmenau.de.

Keywords: Oxygen vacancies, amorphous materials, tin oxide, ordered arrays, sodium-ion batteries

\begin{abstract}
Oxygen vacancies (OVs) are reported for the first time as an effective strategy to boost the electrochemical performance for amorphous electrode materials of sodium-ion batteries (SIB). Amorphous $\mathrm{SnO}_{2}$ is used as a model anode material to demonstrate the significant impact of OVs owing to the high attention it has received in the SIB field. Amorphous $\mathrm{SnO}_{2}$ ordered arrays are fabricated using the nanoimprinted anodic aluminum oxide (AAO) template and atomic layer deposition, and OVs are confined in the material by annealing the arrays in the $\mathrm{N}_{2}$ atmosphere. The OVs-containing amorphous $\mathrm{SnO}_{2}$ ordered arrays, used as binder- and conductive additive-free anodes, exhibit high reversible capacity and good cycle life by retaining the capacities of $376 \mathrm{mAh} \mathrm{g}^{-1}$ after 100 cycles at $0.05 \mathrm{~A} \mathrm{~g}^{-1}$ and $220 \mathrm{mAh} \mathrm{g}^{-1}$ after 800 cycles at $1 \mathrm{~A} \mathrm{~g} \mathrm{~g}^{-1}$ as well as great rate capability by maintaining the capacities of 210 $\mathrm{mAh} \mathrm{g}^{-1}$ at $10 \mathrm{~A} \mathrm{~g}^{-1}$ and $200 \mathrm{mAh} \mathrm{g}^{-1}$ at $20 \mathrm{~A} \mathrm{~g}^{-1}$. Electrochemical kinetic study reveals that the presence of OVs greatly enhances charge transfer/transport in the
\end{abstract}


amorphous $\mathrm{SnO}_{2}$, thereby boosts the performance comparing with the OVs-free counterpart. This work highlights the importance of modulating defects in amorphous electrode materials towards promoted sodium storage. 


\section{Introduction}

Defects play an important part in both the chemical and physical behavior of solids [1-5]. Simple defect modification is a powerful means to improve the performance of electrochemical energy storage devices [6-8]. Defects such as oxygen vacancies (OVs) have received considerable interests in the field of lithium-ion batteries (LIBs). OVs can trigger changes in the chemical and structural characteristics of the active electrode materials as well as the property of the electrode/electrolyte interface without sacrificing crystal stability, so affecting the energetics for electron and ion transport, facilitating the phase transition experienced in lithiation, and modifying surface thermodynamics [9-12]. Recently, sodium-ion batteries (SIBs) come again into focus as the important alternative owing to the low cost of $\mathrm{Na}$ associated with its natural abundance and decent energy density bestowed by its similar chemical nature to Li [13-15]. Despite the rapid progress of SIBs, study of OVs on sodium storage hasn't followed that on LIBs to the same extent as very few reports have shown concerns for this topic so far $[16,17]$. Therefore, it urges us to explore the effects of OVs on the SIB electrodes' performance, and such kind of knowledge is of great importance to develop suitable large-scale electrochemical energy storage devices.

Amorphous materials have a more open framework that can form percolation pathways via the opening of active diffusion channels, thus facilitating the Na-ion diffusion owing to the isotropic characteristic. Such isotropic behavior may help reduce the degradation of the electrode associated with volume changes upon cycling. Studies have shown that Na-ion diffusion in amorphous materials proceeds more 
rapidly than in crystalline counterparts with similar particle size and morphology [18-21]. Thus the amorphous electrode materials sometimes outperformed their crystalline counterpart. Owing to the high attention that has been given to the $\mathrm{SnO}_{2}$-based SIBs in the last few years [22-31], we take a- $\mathrm{SnO}_{2}$ as a model material and highlight for the first time that the sodium storage performance of the amorphous materials can be greatly promoted by the confined OVs. The presented OV-containing a-SnO 2 ordered array anode delivered a capacity of $376 \mathrm{mAh} \mathrm{g}^{-1}\left(0.05 \mathrm{~A} \mathrm{~g}^{-1}\right)$ after 100 cycles and $220 \mathrm{mAh} \mathrm{g}^{-1}\left(1 \mathrm{~A} \mathrm{~g}^{-1}\right)$ after 800 cycles. Moreover, superior rate capability was achieved by retaining the capacities of 210 and $200 \mathrm{mAh} \mathrm{g}^{-1}$ at the rate of 10 and $20 \mathrm{~A} \mathrm{~g} \mathrm{~g}^{-1}$, respectively. Both cyclability and rate capability was greatly enhanced comparing with the OVs-free a- $\mathrm{SnO}_{2}$ arrays. Our study not only demonstrates the advantages of amorphous SIB electrode materials, but also reveals the significant impact of OVs on promoting SIB performance. This approach provides new insight and direction for addressing the challenges of rechargeable SIBs.

In this work, ordered $\mathrm{Ni}$ nanorod arrays as current collector were first prepared using the nanoimprinted anodic aluminum oxide (AAO) template, then a layer of a- $\mathrm{SnO}_{2}$ was deposited on the surface of the $\mathrm{Ni}$ arrays using atomic layer deposition (ALD) followed by a subsequent annealing in $\mathrm{N}_{2}$ atmosphere to obtained the heterostructured arrays. As comparison, the air-annealed arrays were also fabricated and the detailed fabrication process of the ordered arrays is shown in Scheme S1 in the Supporting Information. To demonstrate the OVs' impact, we chose such kind of electrode architecture to exclude some factors that may influence the sodium storage 
performance to the maximum extent under the following considerations. First, the direct deposition of a-SnO $\mathrm{S}_{2}$ on $\mathrm{Ni}$ nanoarray current collector can eliminate the use of conductive additive and binder. Their absence helps to accurately reveal the intrinsic properties of a- $\mathrm{SnO}_{2}$ because the lack of control over how the conductive additive and binder interact with active material at the nanoscale may cause the measured performance to be sensitive to phenomenological effects [32]. Second, the high regularity of the heterostructured nanorods guaranteed by the nanoimprinted AAO templating technique can provide high $\mathrm{Na-ion}$ accessibility from electrolyte and fast electron transport when operated at high rates $[33,34]$. Third, the great integrity of the arrays can minimize the morphological discrepancy after annealing in different atmosphere. All three aspects help to isolate the effect of OVs.

\section{Materials and methods}

\subsection{Materials}

All chemicals were purchased from Alfa Aesar GmBH \& Co KG., and used without further purification

\subsection{Preparation of the AAO template}

AAO template was prepared by the nanoimprinting technique and an anodization process. Aluminum foil (99.99\%) was electrochemically polished in a mixture solution of perchloric acid and ethanol (1:7, v:v) at a voltage of $30 \mathrm{~V}$. The $\mathrm{Ni}$ imprinting stamp was placed on top of the polished $\mathrm{Al}$ foil, and the imprinted $\mathrm{Al}$ foil was obtained by applying a pressure of $\sim 10 \mathrm{kN} \mathrm{cm}^{-2}$ for 3 min by an oil pressing 
system. The anodization of the imprinted Al foil was performed under a voltage of $160 \mathrm{~V}$ in a $\mathrm{H}_{3} \mathrm{PO}_{4}$ solution $\left(\mathrm{H}_{3} \mathrm{PO}_{4}\right.$ :ethylene glycol: $\mathrm{H}_{2} \mathrm{O}=1: 100: 200$, v:v:v) at $2^{\circ} \mathrm{C}$ for $2 \mathrm{~h}$. The anodization voltage was chosen to match the periodic distance of the imprinting stamp according to the linear relationship $\left(2.5 \mathrm{~nm} \mathrm{~V}^{-1}\right)$. Afterward, a thick layer of $\mathrm{Ni}$ was electrochemically deposited on top of the AAO template as current-carrying substrate, before which a $30 \mathrm{~nm}$ thick layer of Au was evaporated by physical vapor deposition (PVD) to improve the adhesion between the Ni layer and the template. The backside $\mathrm{Al}$ was removed by a mixture solution of $\mathrm{CuCl}_{2}$ solution (3.4 $\mathrm{g}$ in $100 \mathrm{~mL} \mathrm{H}_{2} \mathrm{O}$ ) and $\mathrm{HCl}(100 \mathrm{~mL})$. Then, the barrier layer was removed in a 5 wt $\% \mathrm{H}_{3} \mathrm{PO}_{4}$ solution at $60^{\circ} \mathrm{C}$ to form a through-pore AAO template.

\subsection{Fabrication of the ordered Ni nanorod arrays}

The ordered Ni nanorod arrays were electrochemically deposited in Watt's bath as electrolyte, which consists of $\mathrm{NiSO}_{4} \cdot 6 \mathrm{H}_{2} \mathrm{O}(0.38 \mathrm{M}), \mathrm{NiCl}_{2} \cdot 6 \mathrm{H}_{2} \mathrm{O}(0.12 \mathrm{M})$, and $\mathrm{H}_{3} \mathrm{BO}_{3}(0.5 \mathrm{M})$. Two-electrode configuration was used with the as-prepared through-pore AAO template as working electrode and $\mathrm{Ni}$ foil as counter electrode. The electrochemical deposition was performed by constant current mode using a VSP electrochemical workstation (Bio-Logic, France), where a current of $-2 \mathrm{~mA}$ was applied for $6 \mathrm{~min}$. Afterwards, the AAO template was removed in a $5 \mathrm{wt} \% \mathrm{H}_{3} \mathrm{PO}_{4}$ solution at $30^{\circ} \mathrm{C}$.

\subsection{Fabrication of the $\mathrm{OV}$-containing $\mathrm{a}_{-} \mathrm{SnO}_{2}$ ordered arrays}

The OV-containing a- $\mathrm{SnO}_{2}$ ordered arrays were fabricated by depositing a- $\mathrm{SnO}_{2}$ on the surface of the as-prepared Ni nanorod arrays using a PicoSun SUNALE R-150 
ALD system (PicoSun, Finland) according to the following procedure. The reaction chamber was heated to $250^{\circ} \mathrm{C}$, and $\mathrm{SnCl}_{4}$ and $\mathrm{H}_{2} \mathrm{O}$ were chosen as the precursors of Sn and $\mathrm{O}$, respectively. $\mathrm{SnCl}_{4}$ was pulsed for $0.2 \mathrm{~s}$ and purged for $4 \mathrm{~s}$, followed by a 1 s pulse and an $8 \mathrm{~s}$ purge of $\mathrm{H}_{2} \mathrm{O}$ and this procedure was repeated 750 times. To obtain the $\mathrm{N}_{2}$-/air-annealed sample, the as-deposited sample was annealed in $\mathrm{N}_{2} /$ air at $400^{\circ} \mathrm{C}$ for $3 \mathrm{~h}$ with a ramp rate of $10^{\circ} \mathrm{C} / \mathrm{min}$.

\subsection{Characterizations}

X-ray diff raction (XRD) analysis was performed on a SIEMENS/BRUKER D5000 $\mathrm{X}$-ray diff ractometer using $\mathrm{Cu} \mathrm{K} \alpha$ radiation at $40 \mathrm{kV}$ and $40 \mathrm{~mA}$, with the samples being scanned from $2 \theta=20^{\circ}-60^{\circ}$ at rate of $0.02^{\circ} \mathrm{s}^{-1}$ in a Bragg-Brentano geometry. Scanning electron microscopy (SEM) analysis was conducted using a Hitachi S4800 field emission scanning microscopy. Transmission electron microscopy (TEM) analysis was performed on a JEOL 2100F transmission electron microscope. X-ray photoelectron spectra (XPS) were acquired on an ESCALAB 250Xi with Mg Ka (hv $=1253.6 \mathrm{eV})$ as the excitation source. The binding energies obtained in the XPS spectra analysis were corrected for specimen charging by referencing C 1 s to 284.8 eV. Room-temperature electron spin resonance (ESR) spectra were obtained using a JEOL JES-FA200 ESR spectrometer $(300 \mathrm{~K}, 9.062 \mathrm{GHz})$. Raman spectra were recorded with a LABRAM-HR Confocal Laser Micro Raman Spectrometer 750 K.

\subsection{Electrochemical measurements}

Samples were directly used as anodes without adding conductive additive and polymeric binder. Electrochemical tests were carried out using a coin cell 
configuration, CR2032, which were assembled in a nitrogen-filled glovebox with the oxygen and moisture concentrations kept below $0.1 \mathrm{ppm}$. Sodium metal foil used as a counter electrode was separated from the working electrode using a glass microfiber filter (Whatman, grade $\mathrm{GF} / \mathrm{B}$ ) with the pore size of $1 \mu \mathrm{m}$. The electrolyte was $1 \mathrm{M}$ sodium perchlorate $\left(\mathrm{NaClO}_{4}\right)$ in propylene carbonate/ethylene carbonate (1:1). Cyclic voltammetry $(\mathrm{CV})$ was performed on a VSP electrochemical workstation (Bio-Logic, France) in the potential range of 0.01 to $3.0 \mathrm{~V}$ (vs $\mathrm{Na} / \mathrm{Na}^{+}$). Electrochemical impedance spectroscopy (EIS) was performed on the same workstation with a frequency range of $10^{6}-10^{-2} \mathrm{~Hz}$ and a $5 \mathrm{mV}$ AC amplitude. Galvanostatic discharge/charge was carried out on a Land CT2001A battery testing system (Land, China) with the cutoff potentials set to $0.01-3.0 \mathrm{~V}\left(\mathrm{vs} \mathrm{Na} / \mathrm{Na}^{+}\right)$at room temperature.

\section{Results and discussion}

Figure 1a and $\mathbf{b}$ show the representative scanning electron microscope (SEM) images of the as-prepared AAO template with hexagonally arranged pores with a size of $\sim 180 \mathrm{~nm}$. The images clearly demonstrate the long-range and perfect ordering of the pore arrays. The Ni nanorod arrays faithfully reproduced the shape, size, and vertical alignment that derive from the high regularity of the template after the electrochemical deposition and template removal (Figure S1). Guaranteed by the highly ordered and hexagonally arranged Ni nanoarray current collector, these structural features were successfully preserved after the ALD deposition of a-SnO 2 (Figure S2). The diameter increases from $\sim 180 \mathrm{~nm}$ 
to $\sim 200 \mathrm{~nm}$, indicating a thickness of $\sim 10 \mathrm{~nm}$ of the $\mathrm{SnO}_{2}$ layer. Figure 1c and d show the SEM images of the heterostructured nanoarrays after annealing in $\mathrm{N}_{2}$ atmosphere. It can be seen that a large-scale of nanorod arrays was obtained, and no agglomeration or collapse was observed. The nanorods have a diameter of $\sim 200 \mathrm{~nm}$ and length of $\sim 2 \mu \mathrm{m}$ (Figure S3) with a uniform coating of a-SnO 2 . Same results can be found in the arrays annealing in air atmosphere, as displayed in Figure 1e and $\mathbf{f}$. Therefore, we successfully fabricated the $\mathrm{N}_{2}$ - and air-annealed a- $\mathrm{SnO}_{2}$ arrays with the structural features of vertical alignment, high regularity, and ordered arrangement of the nanorods. It is worth emphasizing that minimum morphological discrepancy between the two annealed samples were achieved, which could essentially rule out the morphological effect on the SIB performances when we compare the two samples as the SIB anodes.

The phase of the heterostructured arrays after annealing were examined by X-ray diffraction (XRD) and the patterns are shown in Figure 2a. Apart from the diffraction peaks of $\mathrm{Ni}$ and $\mathrm{Au}$, the absence of the two strongest peaks of the crystalline $\mathrm{SnO}_{2}\left(26.6^{\circ}\right.$ (110) and $33.89^{\circ}$ (101)) [23-25] shows the amorphous nature of the samples, as indicated in the inset of Figure 2a. The energy-dispersive X-ray spectroscopy (EDX) line scan and elemental mapping of an individual $\mathrm{N}_{2}$-annealed $\mathrm{SnO}_{2}$ nanorod verify the presence of $\mathrm{Sn}, \mathrm{Ni}$, and $\mathrm{O}$ (Figure 2b). The elemental distribution of Ni shows a peak located in the center the nanorod, which corresponds to the elemental mapping, where the 
distribution of $\mathrm{Sn}$ and $\mathrm{O}$ show wider diameters than that of $\mathrm{Ni}$, indicating that a-SnO $\mathrm{S}_{2}$ was uniformly coated on the surface of Ni nanorod. A diameter of $\sim 200$ $\mathrm{nm}$ can be seen in Figure $\mathbf{2} \mathbf{b}$ and the uniform diameter along the length of the nanorod once again demonstrates the uniformity of the a-SnO 2 layer. Figure 2c and d show the high-resolution transmission electron microscopy (HRTEM) images of the $\mathrm{N}_{2^{-}}$and air-anneal samples, respectively. The absence of lattice fringes in both samples further confirms the amorphous structure of $\mathrm{SnO}_{2}$. Additionally, the thickness of the $\mathrm{SnO}_{2}$ layer can be determined to be $\sim 10 \mathrm{~nm}$. All the above results are in good agreement with the SEM and XRD analysis.

It is known that OVs can be created by heating nanostructured oxides in oxygen-deficient environment at relatively lower temperature, which could be related to the reduce energies required to remove the oxygen $[35,36]$. X-ray photoelectron spectroscopy (XPS) was used to examine the existence of the OVs. The $\mathrm{O}$ 1s core level spectrum of the air-annealed sample in Figure 3a shows two peaks: the one at $530.3 \mathrm{eV}$ belongs to the Sn-O-Sn bonds and the one at $532.1 \mathrm{eV}$ is due to the absorbed water. One more peak at $531.6 \mathrm{eV}$ appears in the spectrum of the $\mathrm{N}_{2}$-annealed sample, which is attributed to the OVs in the matrix of metal oxide [37-39]. The Sn 3d core level spectra (Figure 3b) show that both the $3 \mathrm{~d} 5 / 2$ and $3 \mathrm{~d} 3 / 2$ peaks of the $\mathrm{N}_{2}$-annealed sample shift towards a lower binding energy by $\sim 0.45 \mathrm{eV}$ comparing with those of the air-annealed sample, which could be caused by the presence of the OVs $[40,41]$. The Sn $3 d$ signals are symmetric and no shoulder peaks appear at the 
lower binding energy side, suggesting that the $\mathrm{OV}$ formation does not accompany the formation of $\mathrm{Sn}^{3+}$. The comparison of the XPS results reveals that annealing in $\mathrm{N}_{2}$ could facilitate the formation of OVs whereas annealing in air could diminish them. The Raman spectra of the two samples show a very broad and intense peak at $\sim 570 \mathrm{~cm}^{-1}$, which suggests an amorphous or disordered phase existed in the material (Figure 3c) [42]. It is worth noting that a hump at $\sim 470 \mathrm{~cm}^{-1}$ emerging in the spectrum of the $\mathrm{N}_{2}$-annealed sample corresponds to the $E_{g}$ mode that is sensitive to OVs and broadening of the $E_{g}$ mode could be caused by the shortening of correlation length resulting from defects like OVs [43,44]. Further proof is provided by the electron spin resonance (ESR) spectroscopy (Figure 3d). The $\mathrm{N}_{2}$-annealed sample exhibits an ESR signal at $g=2.003$ that is assigned to the electrons trapped in the OVs $[45,46]$. Therefore, based on the above characterizations, we are able to confirm the existence of the OVs confined in the a-SnO 2 ordered arrays by annealing in the $\mathrm{N}_{2}$ atmosphere.

To disclose the role of OVs on the sodium storage performance of the a- $\mathrm{SnO}_{2}$ ordered arrays, we tested both samples as binder- and conductive additive-free anodes. The samples show similar cyclic voltammetry (CV) curves as shown in Figure S4. The first cathodic scan exhibited a broad peak starting from $\sim 1.3 \mathrm{~V}$. The first bump at around $1.1 \mathrm{~V}$ is attributed to the formation of solid-electrolyte interface (SEI) layer [23]. The rapid increase of current towards the second bump at $\sim 0.6 \mathrm{~V}$ is ascribed to the reduction of $\mathrm{SnO}_{2}$ 
to $\mathrm{Sn}$, and the sharp peak between 0.6 and $0.01 \mathrm{~V}$ is related to the formation of series of $\mathrm{Na}_{\mathrm{x}} \mathrm{Sn}$ alloy [23,26]. The broad peak disappeared in the following cathodic scans, indicating the irreversible property of the two reactions and corresponding to the irreversible loss of discharge capacity after the first cycle. During the following cycles, the two reactions merged to each other, giving rise to a pair of redox pseak at $\sim 0.83 \mathrm{~V}$ (cathodic) $/ \sim 1.3 \mathrm{~V}$ (anodic) [24]. The charge-discharge profiles (Figure 4a and S5) are in agreement with the corresponding $\mathrm{CV}$ results. It is worth noting that the $\mathrm{N}_{2}$-annealed sample has a smaller voltage separation $(0.46 \mathrm{~V})$ of the redox pair than that of the air-annealed sample $(0.53 \mathrm{~V})$, giving a first hint of better charge diffusion for reversible sodium storage upon introducing the OVs. Further demonstration of the benefits of OVs is given by the analysis of cycling performance (Figure 4b). Comparing with the air-annealed sample (1008.9 $\left.\mathrm{mAh}^{-1}\right)$, the $\mathrm{N}_{2}$-annealed sample delivered the higher first discharge capacities of 1174.4 $\mathrm{mAh} \mathrm{g}^{-1}$ at $0.05 \mathrm{~A} \mathrm{~g}^{-1}$ rate and a higher initial coulombic efficiency (CE) ( $40.0 \%$ vs. $21.6 \%$ ) with it faster reaching over $90 \%$ (cycle10 vs. cycle22). The relatively low initial $\mathrm{CE}$ agrees with the $\mathrm{CV}$ results and the general results observed of $\mathrm{SnO}_{2}$ systems that have been tested in the $\mathrm{Na}$ half-cells $[24,27,28,47,48]$, which could be attributed to the formation of SEI layer in the first cycle and partial reversible conversion reaction due to the irreversible binding of $\mathrm{Na}$ with oxygen according to the recent work [25]. The $\mathrm{N}_{2}$-annealed sample exhibited better cycling performance too, maintaining a capacity of 376 
$\mathrm{mAh} \mathrm{g}^{-1}$ at cycle100, while the air-annealed sample retained a capacity of 289 $\mathrm{mAh} \mathrm{g}^{-1}$ at cycle100. The OVs not only promotes the cycling performance of the electrode, but also significantly enhances the rate capability. Figure $\mathbf{4 c}$ compares the rate performance of the two samples in the current range of 0.1-20 A g $\mathrm{A}^{-1}$. The $\mathrm{N}_{2}$-annealed sample exhibited impressive capacities of 330 , $300,277,253$, and $225 \mathrm{mAh} \mathrm{g}^{-1}$ at the rates of $0.2,0.5,1,2$, and $5 \mathrm{~A} \mathrm{~g} \mathrm{~g}^{-1}$, respectively. When the rate increased to as high as 10 and $20 \mathrm{~A} \mathrm{~g}^{-1}$, the values of 210 and $200 \mathrm{mAh} \mathrm{g}^{-1}$ were still retained, respectively, and fully recovered after reducing back to $0.05 \mathrm{~A} \mathrm{~g}^{-1}$. The corresponding charge-discharge profiles at various rates are shown in Figure S6. It can be found that the $\mathrm{N}_{2}$-annealed sample showed much less polarization at high rates then the air-annealed sample. To the best of our knowledge, the presented results are among the best rate capability of the reported $\mathrm{SnO}_{2}$-based SIB anodes [23-28]. It is no surprise to observe that the air-annealed sample showed lower values at all rates (237, 193, 155, 116, 70, 50, and $41 \mathrm{mAh} \mathrm{g}^{-1}$ at $0.2,0.5,1,2,5,10$, and $20 \mathrm{~A} \mathrm{~g}^{-1}$, respectively). Moreover, when cycled at the rate of $1 \mathrm{~A} \mathrm{~g}^{-1}$, the $\mathrm{N}_{2}$-annealed sample maintained a capacity of $220 \mathrm{mAh} \mathrm{g}^{-1}$ after 800 cycles (Figure 4d), indicating the great long-term stability at high current. Overall, the above results clearly demonstrate that the OVs can effectively enhance the sodium storage performance of the amorphous SIB electrode materials.

In order to confirm the facilitation of the charge transfer/transport induced by the OVs, we carried out electrochemical kinetic study on the samples. First, 
CVs were performed in the range of $0.1-20 \mathrm{mV} \mathrm{s}^{-1}$ (Figure 5a and S7). Because it is difficult to separate the conversion and alloy peaks for the sodiation process at all scan rates, we took the broad desodiation peak near $1.4 \mathrm{~V}$ as the monitoring peak. One can expect that increased peak current (i) and shifting peak voltage were observed with increasing the scan rate $(v)$. According to the general expression of $i=a v^{b}$ where $a$ and $b$ are adjustable constants, the $b$-value would be 0.5 for an ideal semi-infinite linear diffusion controlled process while close to 1.0 for a surface controlled process $[49,50]$. As shown in Figure 5b, for the case of the $\mathrm{N}_{2}$-annealed sample, the $b$-value remains 0.87 up to the scan rate of $5 \mathrm{mV} \mathrm{s}^{-1}$ and slightly decreases to 0.73 at higher rates, indicating that the desodiation process starts gradually transitioning from surface control to solid-state diffusion control. For the case of the air-annealed sample, the transition starts at the lower scan rate of $0.5 \mathrm{mV} \mathrm{s}^{-1}$ ( $b$-value: 0.81-0.67). Although it is not possible to completely identify this transition of the desodiation reaction to either dealloying or conversion, one can safely state that diffusion control in the air-annealed sample is a graver issue than in the $\mathrm{N}_{2}$-annealed sample [24], which agrees well with the rate performances.

Second, electrochemical impedance spectroscopy (EIS) measurements were performed and the Nyquist plots were collected after the 2nd and 50th cycles (Figure 6a and b). Simultaneously, both EIS measurements exhibit a compressed semicircle in the high- and medium-frequency range followed in a linear section in the low-frequency range. In general, the $\mathrm{N}_{2}$-annealed sample 
possesses smaller impedance than the air-annealed sample during the entire cycling. The equivalent circuit modeling is (inset of Figure 6c) is used to analyze the results after 50 cycles in order to gain better understandings, where $R_{\text {int }}$ is the interface resistance related to SEI layer, $R_{c t}$ is the charge transfer resistance, and $W_{o}$ is the Warburg impedance related to the diffusion of Na-ions into the bulk electrode. As suggested from the fitting results (Table S1), the charge transfer and transport resistance were largely reduced for the $\mathrm{N}_{2}$-annealed sample compared to the air-annealed sample. $R_{\text {int }}$ is reduced in the $\mathrm{N}_{2}$-annealed sample from 4.8 to $2.0 \Omega$, accompanied by its charge capacitance decreasing from $3.14 \times 10^{-5}$ to $1.93 \times 10^{-5} \mathrm{~F}$. $R_{c t}$ is also reduced from 372.5 to 258.0 $\Omega$ accompanied with the reduced capacitance as well. The lower charge capacitance (or charge accumulation) at the interfaces could lead to the reduced charge transfer resistance, possibly due to the better adsorption and penetration into the amorphous layer in the $\mathrm{N}_{2}$-anneal sample with the existence of the OVs [51]. The charge transport resistance $\left(W_{o}-R\right)$ in the $\mathrm{N}_{2}$-annealed sample is much smaller (173.5 $\Omega$ ) than that in the air-annealed sample (475.1 $\Omega$ ), which indicates much better charge diffusion that could induce much better rate capability and further verifies the benefits of the OVs on charge transport. In addition, Na-ion diffusion coefficients $\left(D_{\mathrm{Na}}\right)$ were calculated from the low frequency Warburg contribution [52], shown as the sloping lines, that is associated with the diffusion of Na-ions in the bulk electrode (Figure S8) and the results are shown in Figure 6d. It can be estimated that the $D_{\mathrm{Na}}$ of the 
$\mathrm{N}_{2}$-annealed sample is $3.31 \times 10^{-13} \mathrm{~cm}^{2} \mathrm{~s}^{-1}$ and is almost 9.4 times as much as that of the air-annealed sample $\left(3.51 \times 10^{-14} \mathrm{~cm}^{2} \mathrm{~s}^{-1}\right)$. Therefore, our electrochemical kinetic study reveals that the existence of the OVs can reduce charge transfer and transport resistance, so the sodium storage performance is largely improved.

\section{Conclusion}

In conclusion, we have fabricated amorphous $\mathrm{SnO}_{2}$ ordered arrays through a nanoimprinted template-assisted method and employed them as binder- and conductive additive-free anodes for SIBs. We have shown that the OV-containing amorphous $\mathrm{SnO}_{2}$ arrays anode exhibited largely enhanced battery performance comparing to the OV-free counterpart. The OV-containing anode delivered high reversible capacity and good cycling life by retaining the capacities of $376 \mathrm{mAh} \mathrm{g}^{-1}$ at $0.05 \mathrm{~A} \mathrm{~g}^{-1}$ after 100 cycles and $220 \mathrm{mAh} \mathrm{g}^{-1}$ at $1 \mathrm{~A}$ $\mathrm{g}^{-1}$ after 800 cycles. Moreover, impressive rate capability was also achieved by maintaining the capacities of 210 and $200 \mathrm{mAh} \mathrm{g}^{-1}$ at the rates as high as 10 and $20 \mathrm{~A} \mathrm{~g} \mathrm{~g}^{-1}$. The performance enhancement is attributed to the improvement of charge transfer/transport, as evidenced by the analysis of the electrochemical kinetics. This work provides the first demonstration of the benefits of OVs in amorphous SIB electrode materials. The presented results point out a promising direction towards promoted sodium storage by creating and modulating OVs confined in the electrode materials. Given the rapidly growing attention paid to 
SIBs, we hope that our work can intrigue more future studies on utilizing defects in this exciting field.

\section{Acknowledgements}

This work is financially supported by the European Research Council (ThreeDsurface, 240144 and HiNaPc, 737616), BMBF (ZIK-3DNanoDevice, 03Z1MN11), German

Research Foundation (DFG: LE 2249_4-1), National Natural Science Foundation of China (21577086), and Shanghai Thousand Talent Plan. We thank Dr. Xiaodong Zhang for his assistant for the XPS, Raman and ESR measurements.

\section{Appendix A. Supplementary material}

Supplementary data associated with this article can be found in the online version at http://...

\section{Appendix B. Figures and caption}

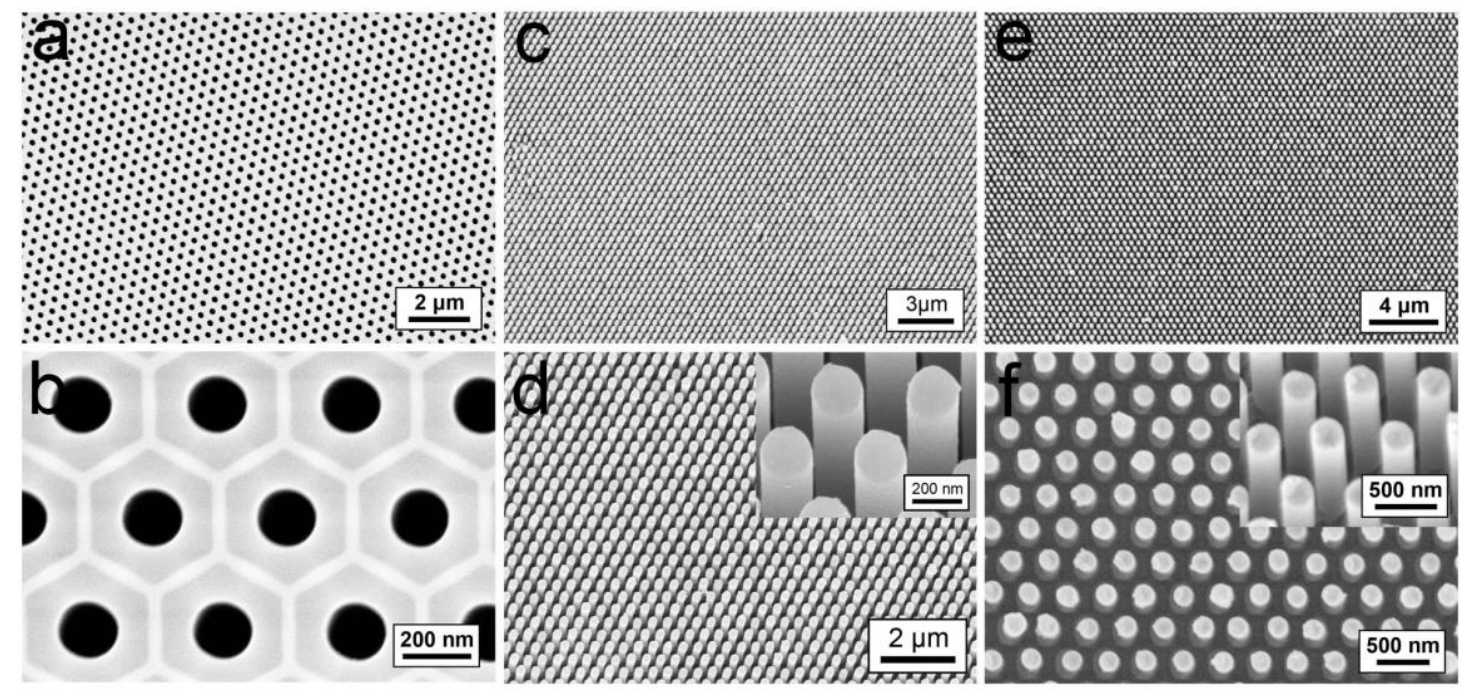


Figure 1. SEM images of AAO template ( $a$ and b), $\mathrm{N}_{2}$-annealed (c and d) and air-annealed ordered arrays (e and f).
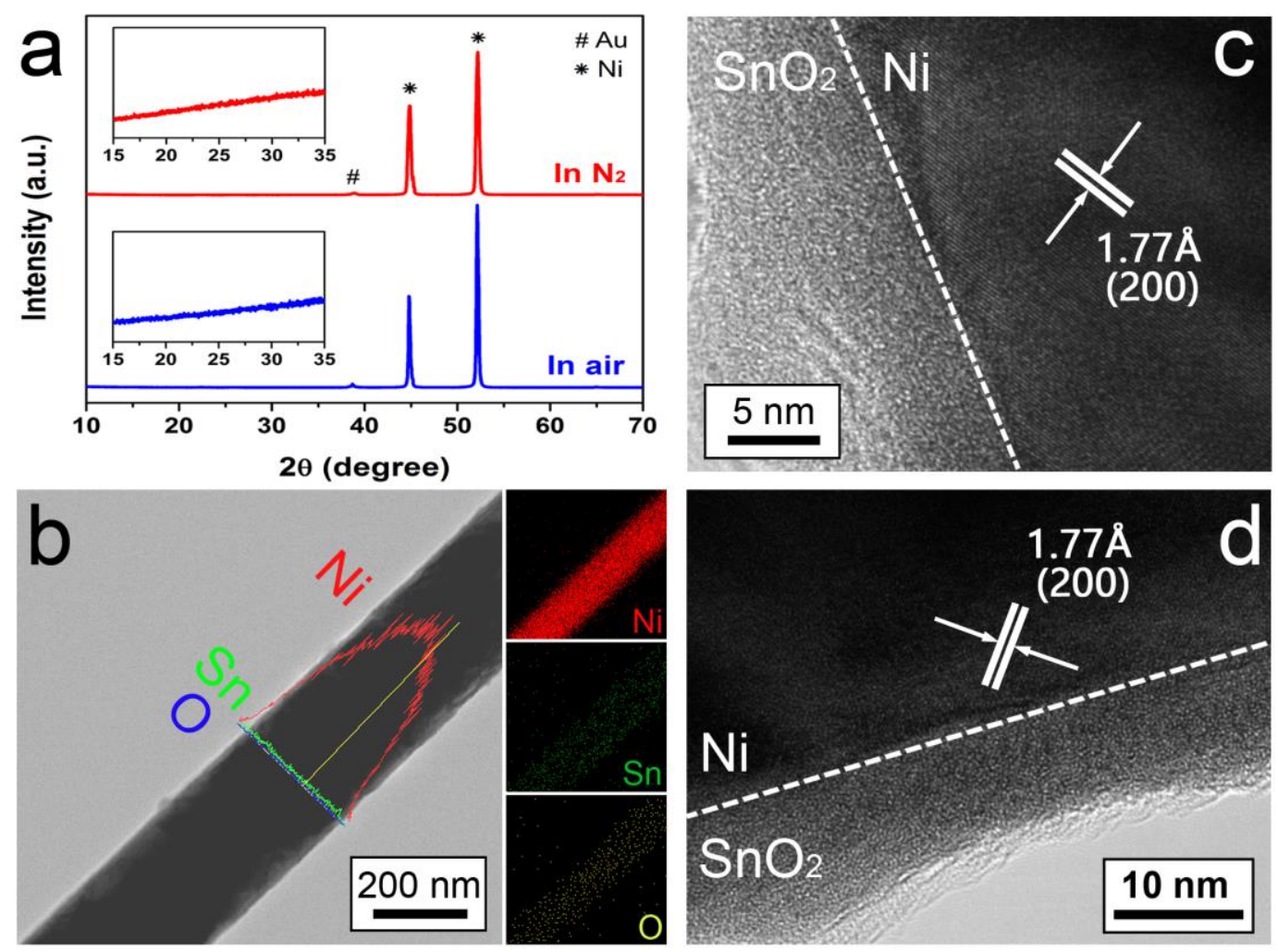

Figure 2. (a) XRD patterns of the ordered arrays (inset shows the enlarged range from $15^{\circ}$ to $35^{\circ}$ ). (b) EDX line scan and elemental mapping of the $\mathrm{N}_{2}$-annealed arrays. (c and d) HRTEM images of the $\mathrm{N}_{2}$-annealed (c) and air-annealed arrays (d). 

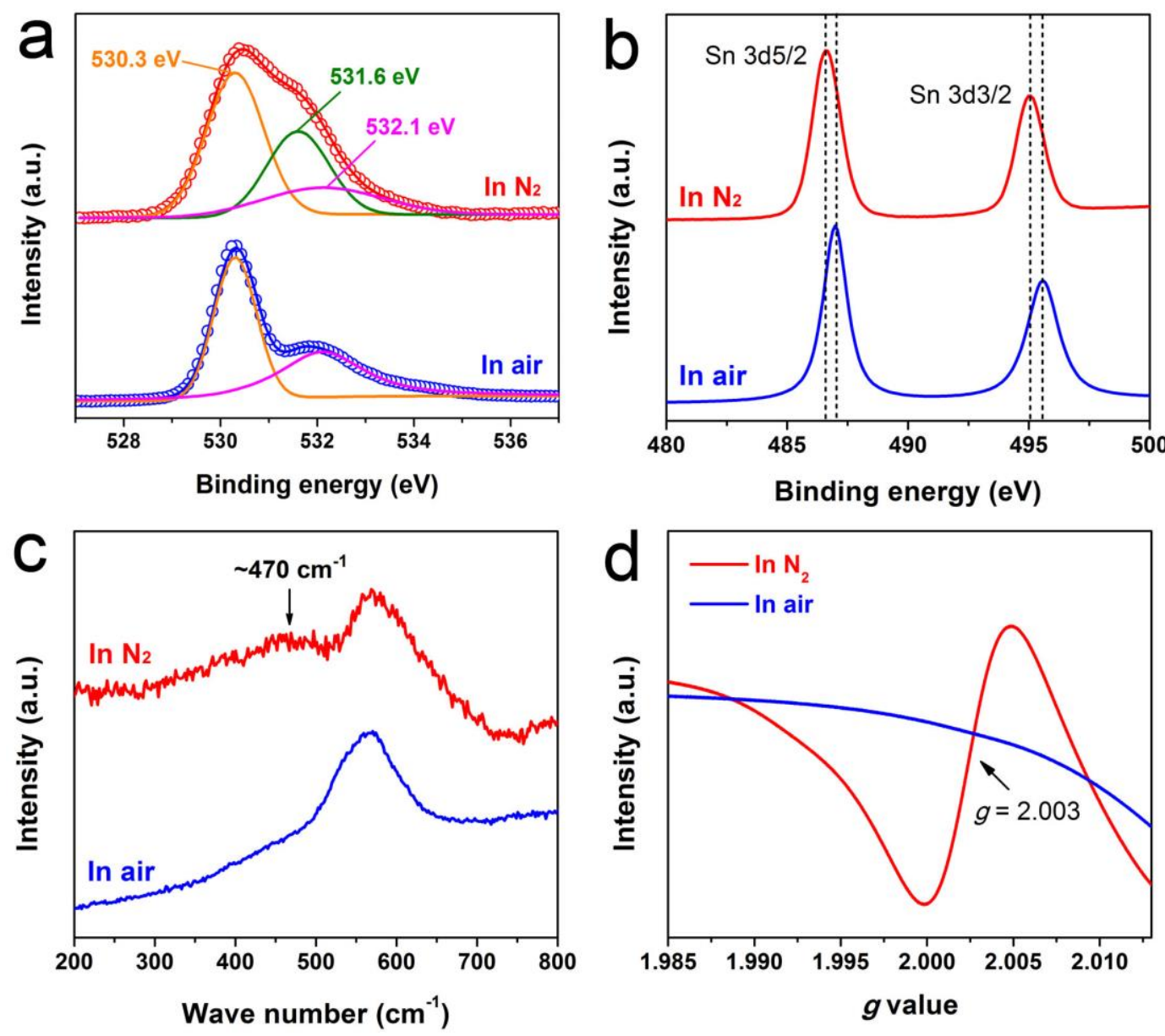

Figure 3. Characterizations of the $\mathrm{N}_{2^{-}}$and air-annealed samples: (a) $\mathrm{O}$ 1s XPS spectra; (b) Sn 3d XPS spectra; (c) Raman spectra; (d) ESR spectra. 

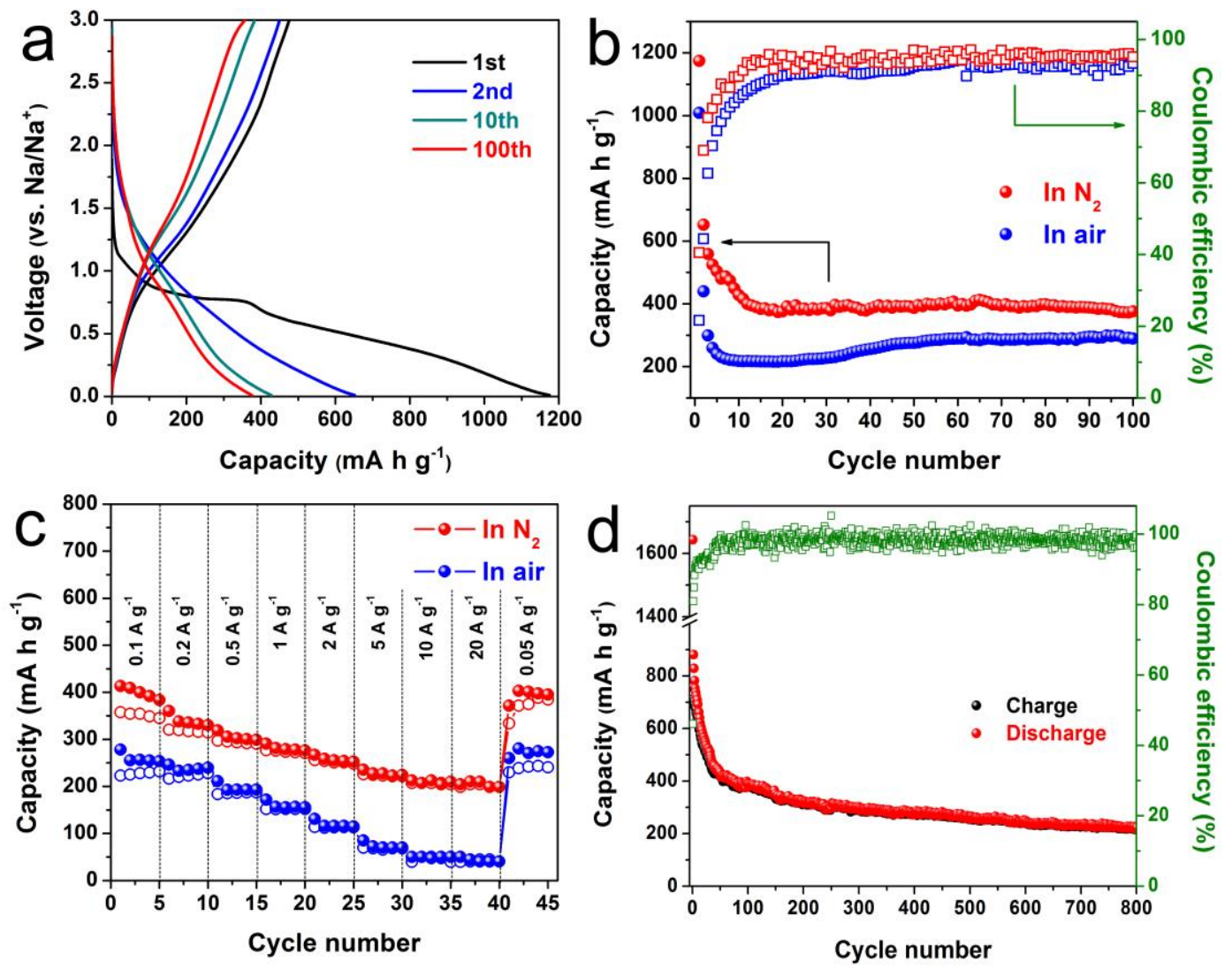

Figure 4. Sodium storage performances: (a) charge-discharge profiles of the $\mathrm{N}_{2}$-annealed sample at $0.05 \mathrm{~A} \mathrm{~g} \mathrm{~g}^{-1}$; (b) comparison of the discharge capacity at $0.05 \mathrm{~A}$ $\mathrm{g}^{-1}$; (c) comparison of the rate performance from 0.1 to $20 \mathrm{~A} \mathrm{~g}^{-1}$; (d) cycling performance of the $\mathrm{N}_{2}$-annealed sample at $1 \mathrm{~A} \mathrm{~g}^{-1}$.
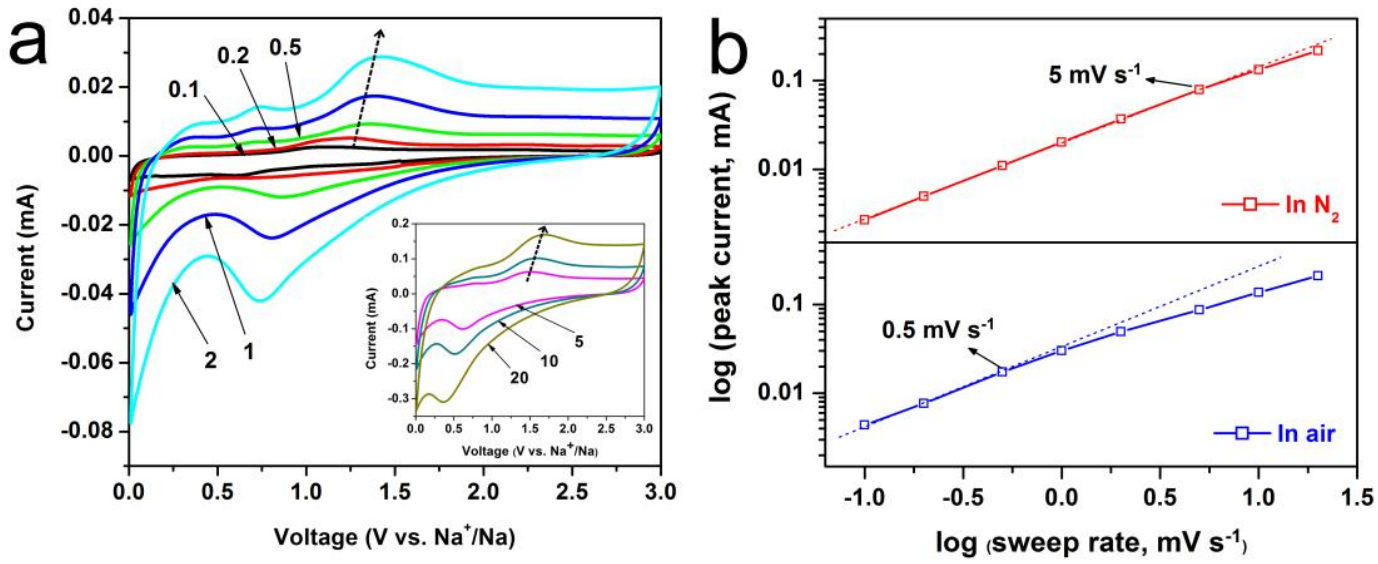

Figure 5. (a) $\mathrm{CV}$ curves of the $\mathrm{N}_{2}$-annealed sample recorded at 1.0 to $20 \mathrm{mV} \mathrm{s}^{-1}$. (b) $b$-value determination from the peak currents of the two samples. 

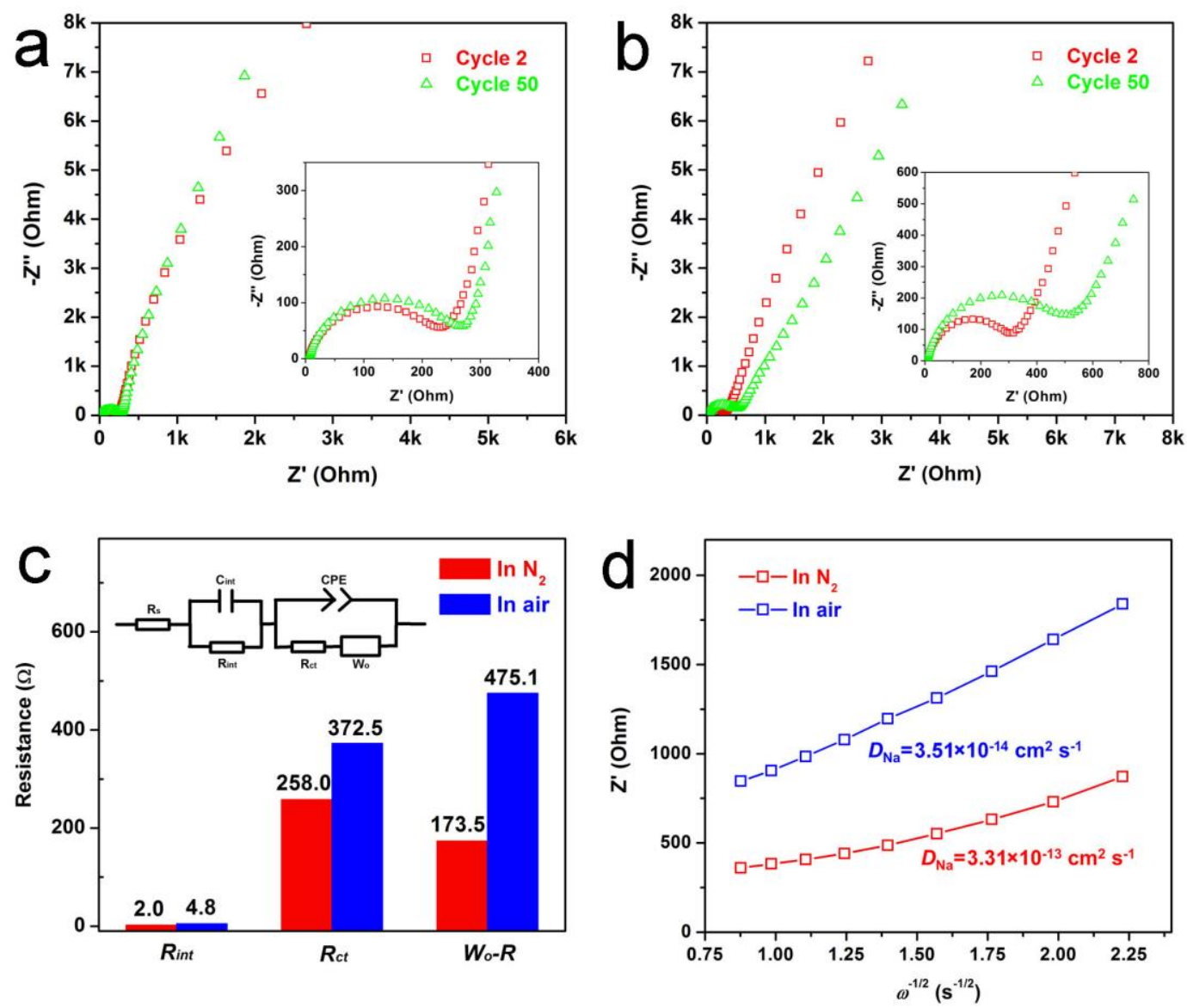

Figure 6. Nyquist plots of the $\mathrm{N}_{2}$-annealed (a) and air-annealed samples (b) recorded after the 2nd and 50th cycle, the insets show the details at high frequency range. (c) Comparison of the resistance (inset shows the equivalent circuit). (d) $Z^{\prime} v s . \omega^{-1 / 2}$ plots in the low frequency region obtained from the Nyquist plots after 50 cycles.

\section{Reference}

[1] S. Lee, G. Nam, J. Sun, J.S. Lee, H.W. Lee, W. Chen, J. Cho, Y. Cui, Angew. Chem. Int. Ed. 55 (2016) 8599-8604.

[2] M. Casas-Cabanas, G. Binotto, D. Larcher, A. Lecup, V. Giordani, J.-M. Tarascon, Chem. Mater. 21 (2009) 1939-1947.

[3] Y. Sun, S. Gao, F. Lei, C. Xiao, Y. Xie, Acc. Chem. Res. 48 (2014) 3-12. 
[4] C.A. Trickett, K.J. Gagnon, S. Lee, F. Gándara, H.B. Bürgi, O.M. Yaghi, Angew. Chem. Int. Ed. 54 (2015) 11162-11167.

[5] M.R. Langille, M.L. Personick, C.A. Mirkin, Angew. Chem. Int. Ed. 52 (2013) 13910-13940.

[6] J. Lee, A. Urban, X. Li, D. Su, G. Hautier, G. Ceder, Science, 343 (2014) 519-522.

[7] M. Park, I.Y. Jeon, J. Ryu, J.B. Baek, J. Cho, Adv. Energy Mater. 5 (2015) 1401550.

[8] J.-H. Lee, R. Black, G. Popov, E. Pomerantseva, F. Nan, G.A. Botton, L.F. Nazar, Energy Environ. Sci. 5 (2012) 9558-9565.

[9] R. Schaub, E. Wahlström, A. Rønnau, E. Lægsgaard, I. Stensgaard, F. Besenbacher, Science 299 (2003) 377-379.

[10] P.V. Sushko, K.M. Rosso, J.G. Zhang, J. Liu, M.L. Sushko, Adv. Funct. Mater. 23 (2013) 5530-5535.

[11] J. Song, D.W. Shin, Y. Lu, C.D. Amos, A. Manthiram, J.B. Goodenough, Chem. Mater. 24 (2012) 3101-3109.

[12] D. Liu, Y. Liu, B.B. Garcia, Q. Zhang, A. Pan, Y.-H. Jeong, G. Cao, J. Mater. Chem. 19 (2009) 8789-8795.

[13] N. Yabuuchi, K. Kubota, M. Dahbi, S. Komaba, Chem. Rev. 114 (2014) 11636-11682.

[14] D. Kundu, E. Talaie, V. Duffort, L.F. Nazar, Angew. Chem. Int. Ed. 54 (2015) 3431-3448.

[15] Y. Xu, M. Zhou, Y. Lei, Adv. Energy Mater. 6 (2016) 1502514. 
[16] J. Chen, Z. Ding, C. Wang, H. Hou, Y. Zhang, C. Wang, G. Zou, X. Ji, ACS Appl. Mater. Interfaces 8 (2016) 9142-9151.

[17] Y. Xu, M. Zhou, X. Wang, C. Wang, L. Liang, F. Grote, M. Wu, Y. Mi, Y. Lei, Angew. Chem. Int. Ed. 54 (2015) 8768-8771.

[18] E. Uchaker, Y. Zheng, S. Li, S. Candelaria, S. Hu, G. Cao, J. Mater. Chem. A 2 (2014) 18208-18214.

[19] W. Wang, S. Wang, H. Jiao, P. Zhan, S. Jiao, Phys. Chem. Chem. Phys. 17 (2015) 4551-4557.

[20] J. Zhu, D. Deng, J. Phys. Chem. C 119 (2015) 21323-21328.

[21] L. Fan, X. Li, B. Yan, J. Feng, D. Xiong, D. Li, L. Gu, Y. Wen, S. Lawes, X. Sun, Adv. Energy Mater. 6 (2016) 1502057.

[22] Z. Li, J. Ding, D. Mitlin, Acc. Chem. Res. 48 (2015) 1657-1665.

[23] Y. Zhao, C. Wei, S. Sun, L.P. Wang, Z.J. Xu, Adv. Sci. 2 (2015) 1500097.

[24] Z. Li, J. Ding, H. Wang, K. Cui, T. Stephenson, D. Karpuzov, D. Mitlin, Nano Energy 15 (2015) 369-378.

[25] J. Ding, Z. Li, H. Wang, K. Cui, A. Kohandehghan, X. Tan, D. Karpuzov, D. Mitlin, J. Mater. Chem. A 3 (2015) 7100-7111.

[26] Y.-X. Wang, Y.-G. Lim, M.-S. Park, S.-L. Chou, J.H. Kim, H.-K. Liu, S.-X. Dou, Y.-J. Kim, J. Mater. Chem. A 2 (2014) 529-534.

[27] X. Xie, S. Chen, C. Wang, G. Wang, ChemSusChem, 8 (2015) 2948-2955.

[28] R.S. Kalubarme, J.-Y. Lee, C.-J. Park, ACS Appl. Mater. Interfaces 7 (2015) $17226-17237$. 
[29] X. Xie, D. Su, J. Zhang, S. Chen, A.K. Mondal, G. Wang, Nanoscale 7 (2015) 3164-3172.

[30] D. Su, C. Wang, H. Ahn, G. Wang, Phys. Chem. Chem. Phys. 15 (2013) 12543-12550.

[31] Y. Zhang, J. Xie, S. Zhang, P. Zhu, G. Cao, X. Zhao, Electrochimica Acta 151 (2015) 8-15.

[32] G. Liu, H. Zheng, X. Song, V.S. Battaglia, J. Electrochem. Soc. 159 (2012) A214-A221.

[33] L. Liang, Y. Xu, C. Wang, L. Wen, Y. Fang, Y. Mi, M. Zhou, H. Zhao, Y. Lei, Energy Environ. Sci., 8 (2015) 2954-2962.

[34] Y. Xu, M. Zhou, L. Wen, C. Wang, H. Zhao, Y. Mi, L. Liang, Q. Fu, M. Wu, Y. Lei, Chem.Mater. 27 (2015) 4274-4280.

[35] M. Salari, K. Konstantinov, H.K. Liu, J. Mater. Chem. 21 (2011) 5128-5133.

[36] X. Pan, M.-Q. Yang, X. Fu, N. Zhang, Y.-J. Xu, Nanoscale 5 (2013) 3601-3614.

[37] J. Gan, X. Lu, J. Wu, S. Xie, T. Zhai, M. Yu, Z. Zhang, Y. Mao, S.C.I. Wang, Y. Shen, Sci. Rep. 3 (2013) 1021.

[38] J. Bao, X. Zhang, B. Fan, J. Zhang, M. Zhou, W. Yang, X. Hu, H. Wang, B. Pan, Y. Xie, Angew. Chem. Int. Ed. 54 (2015) 7399-7404.

[39] Y. Xu, L. Zheng, Y. Xie, Dalton Trans. 39 (2010) 10729-10738.

[40] M. Wu, X. Lin, W. Guo, Y. Wang, L. Chu, T. Ma, K. Wu, Chem. Comm. 49 (2013) 1058-1060. 
[41] J. Szuber, G. Czempik, R. Larciprete, D. Koziej, B. Adamowicz, Thin Solid Films 391 (2001) 198-203.

[42] A. Dieguez, A. Romano-Rodriguez, A. Vila, J. Morante, J. Appl. Phys. 90 (2001) $1550-1557$.

[43] A. Naldoni, M. Allieta, S. Santangelo, M. Marelli, F. Fabbri, S. Cappelli, C.L. Bianchi, R. Psaro, V. Dal Santo, J. Am. Chem. Soc. 134 (2012) 7600-7603.

[44] K. Vijayarangamuthu, S. Rath, J. Alloys Compd. 610 (2014) 706-712.

[45] F. Lei, Y. Sun, K. Liu, S. Gao, L. Liang, B. Pan, Y. Xie, J. Am. Chem. Soc. 136 (2014) 6826-6829.

[46] X. Pan, Y.-J. Xu, J. Phys. Chem. C 117 (2013) 17996-18005.

[47] Y. Wang, D. Su, C. Wang, G. Wang, Electrochem. Commun. 29 (2013) 8-11.

[48] J. Park, J.-W. Park, J.-H. Han, S.-W. Lee, K.-Y. Lee, H.-S. Ryu, K.-W. Kim, G. Wang, J.-H. Ahn, H.-J. Ahn, Mater. Res. Bull. 58 (2014) 186-189.

[49] V. Augustyn, J. Come, M.A. Lowe, J.W. Kim, P.-L. Taberna, S.H. Tolbert, H.D. Abruña, P. Simon, B. Dunn, Nat. Mater. 12 (2013) 518-522.

[50] H. Lindström, S. Södergren, A. Solbrand, H. Rensmo, J. Hjelm, A. Hagfeldt, S.-E. Lindquist, J. Phys. Chem. B 101 (1997) 7717-7722.

[51] T. Xia, W. Zhang, J. Murowchick, G. Liu, X. Chen, Nano Lett. 13 (2013) 5289-5296.

[52] Y. Wang, H. Liu, K. Wang, H. Eiji, Y. Wang, H. Zhou, J. Mater. Chem. 19 (2009) 6789-6795. 


\section{Vitae}

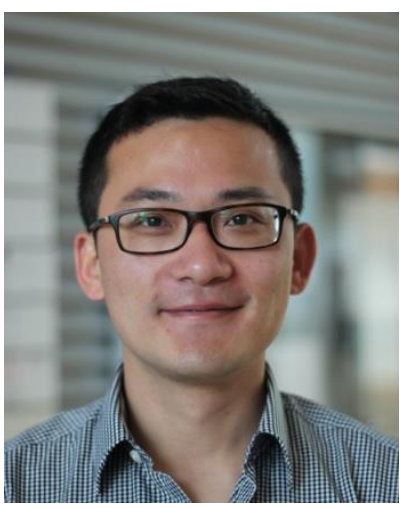

Dr. Yang Xu received his Ph.D. degree under the supervision of Prof. Yi Xie in the Hefei National Laboratory for Physical Sciences at the Microscale, University of Science and Technology of China in 2011. He joined Prof. Yong Lei's group in the Ilmenau University of Technology, Germany, as a senior scientist in 2013. His present research interest includes the synthesis of functional nanomaterials and the design of devices for electrochemical energy storage and conversion.

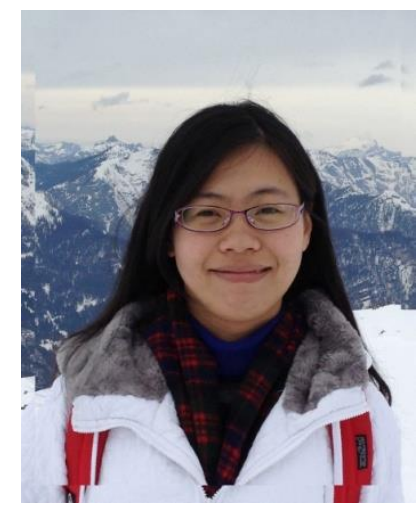

Dr. Min Zhou received Ph.D. degree under the supervision of Prof. Yi Xie in the Department of Chemistry, University of Science and Technology of China in 2012. She is currently a senior scientist in the group of Prof. Yong Lei in Ilmenau University of Technology, Germany. Her research focuses on design of functional nanomaterials and devices for energy storage and conversion. 


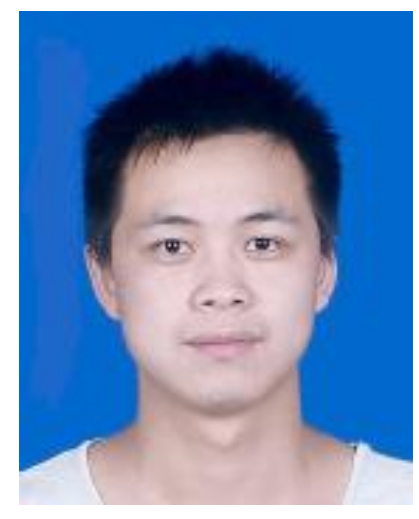

Mr. Chenglin Zhang is a master degree candidate in the School of Environmental and Chemical Engineering at Shanghai University, China. He received his B.S. degree in Applied Chemistry from the Hubei Engineering University in 2014. His main research interests are the construction and functionalization of nanomaterials for energy storage and conversion devices.

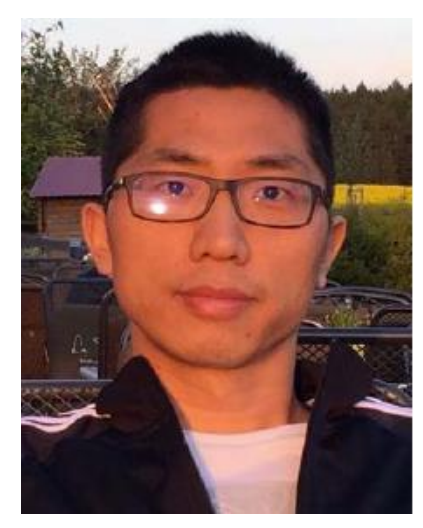

Dr. Chengliang Wang received his bachelor degree in Chemistry from Nanjing University in 2005 and Ph.D. degree from the Institute of Chemistry, Chinese Academy of Sciences (CAS) in 2010. He worked in the Group of Prof. Lei's in TU-Ilmenau as a scientist between 2012 and 2016. He was selected in the National 1000-Talents Program for Young Scholars in 2016 and joined Huazhong University of Science and Technology as a Professor in July 2016. His research topics include 
the design and synthesis of novel organic conjugated materials, crystals and their applications in optoelectronics and energy storage.

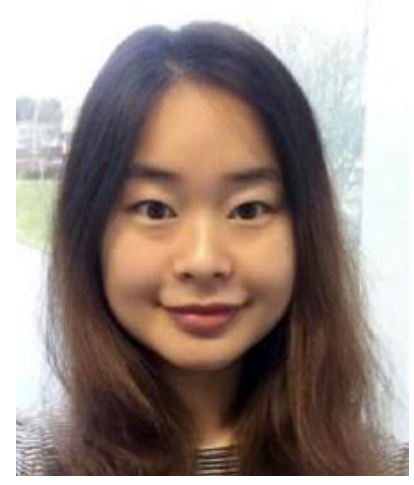

Ms. Liying Liang received her Master degree in the institute of Science, Beijing University of Chemical Technology in 2013. She is currently working in her Ph.D. program under the supervision of Prof. Yong Lei at the Ilmenau University of Technology. Her research interest focuses on materials design for energy storage and conversion systems.

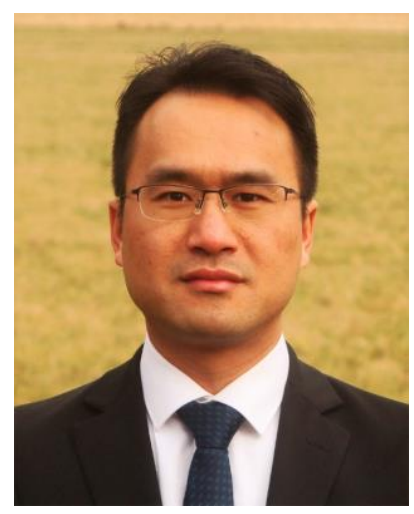

Dr. Yaoguo Fang received M.Sc. degree in 2011 from Shanghai University, China and Ph.D. degree in 2017 from the Institute of Physics, Ilmenau University of Technology, Germany, under the supervision of Prof. Yong Lei. Currently he is a postdoctoral fellow in the group of Prof. Yong Lei. His research work includes design 
and synthesis of nanomaterials and their applications in optoelectronics and energy storage.

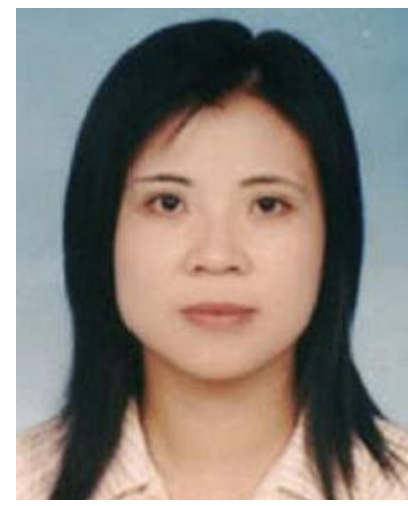

Prof. Minghong Wu received her Ph.D. degree from Shanghai Institute of Nuclear Research, Chinese Academy of Sciences in 1999. Then, she joined Shanghai University. She is the Chang Jiang scholar, the foreign Member of the Russian Academy of Sciences and the recipient of the National Science Fund for Distinguished Young Scholar. Her research interest focuses on application of irradiation technology in environment, application of irradiation technology to the preparation and modification of materials and health impact of environmental pollutants.

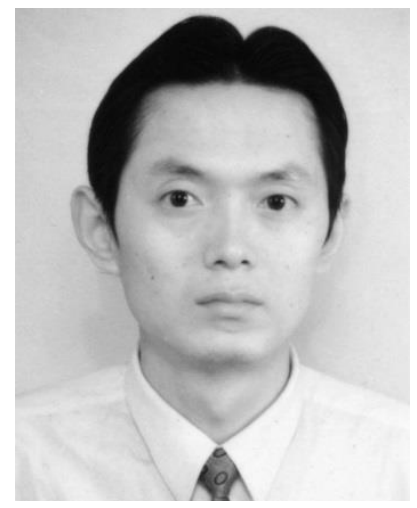


Prof. Yong Lei received his Ph.D. degree from the Chinese Academy of Sciences in 2001. After two years of postdoc research at Singapore-MIT Alliance, he worked as an Alexander von Humboldt Fellow at the Karlsruhe Institute of Technology in 2003-2006. Later he worked at the University of Muenster as a group leader (2006-2009) and a W1 professor (2009-2011). In 2011, he joined the Ilmenau University of Technology as a Chair Professor. His current research interests focuses on template-based nanostructuring, energy-related devices and optoelectronic applications of functional nanostructures and surface nano-patterns. 